\title{
Non-vitamin K oral anticoagulants for coronary or peripheral artery disease: a systematic review and meta-analysis of mortality and major bleeding
}

Nagy, Ádám ; Kim, Jun H ; Jeong, Myeong E ; Heo, Min H ; Putzu, Alessandro ; Belletti, Alessandro ; Biondi-Zoccai, Giuseppe ; Landoni, Giovanni

\begin{abstract}
INTRODUCTION Several high quality randomized controlled studies were recently published on non-vitamin $\mathrm{K}$ oral anticoagulants (NOACs) in patients with or at risk for coronary artery (CAD) or peripheral artery disease (PAD). While a reduction on cardiovascular event is known and an increase in moderate bleeding is expected, the effect of this strategy on survival is currently unknown. Accordingly, we performed a comprehensive systematic review and meta-analysis of randomized controlled trials to investigate the effect of NOAC on survival. EVIDENCE ACQUISITION We searched Pubmed, EMBASE, Cochrane Central Register, and Clinicaltrials.gov (last updated March 31st 2019). The primary endpoint was all-cause mortality at the longest reported follow-up. Coprimary endpoint was major bleeding according to the International Society on Thrombosis and Hemostasis (ISTH) criterion. EVIDENCE SYNTHESIS We included ten randomized controlled trials comparing NOACs versus control treatment (placebo, single platelet or dual antiplatelet therapy) enrolling 66665 patients with or at risk for CAD or PAD. NOACs were associated with a decreased risk of mortality (825/41655 [4.4\%] versus 405/25010 [5.6\%] RR 0.93 [95\% CI: 0.87-1.00], $\mathrm{P}=0.04)$, and an increased risk for major bleeding ( $\mathrm{RR} 1.62[95 \%$ CI: 1.23-2.13], $\mathrm{P}=0.0005)$ when compared to control. Findings were robust to trial sequential, subgroup, and sensitivity analyses. Low doses NOACs were associated with a reduced mortality when compared to standard dose NOACs. CONCLUSIONS NOACs reduced all-cause mortality in patients with or at risk for $\mathrm{CAD}$ or $\mathrm{PAD}$, even though they increased the risk of major bleeding. Future studies regarding the best doses of NOACs are warranted.
\end{abstract}

DOI: https://doi.org/10.23736/S0026-4725.19.05043-6

Posted at the Zurich Open Repository and Archive, University of Zurich ZORA URL: https://doi.org/10.5167/uzh-180601

Journal Article

Originally published at:

Nagy, Ádám; Kim, Jun H; Jeong, Myeong E; Heo, Min H; Putzu, Alessandro; Belletti, Alessandro; Biondi-Zoccai, Giuseppe; Landoni, Giovanni (2019). Non-vitamin K oral anticoagulants for coronary or peripheral artery disease: a systematic review and meta-analysis of mortality and major bleeding. Minerva Cardioangiologica, 67(6):477-486.

DOI: https://doi.org/10.23736/S0026-4725.19.05043-6 


\title{
Non-vitamin K oral anticoagulants for coronary or peripheral artery disease: a systematic review and meta-analysis of mortality and major bleeding
}

\author{
Ádám NAGY 1,2, Jun H. KIM 1,3,4, Myeong E. JEONG 4, Min H. HEO 4, Alessandro PUTZU 5, \\ Alessandro BELLETTI ${ }^{1}$, Giuseppe BIONDI-ZOCCAI 6, 7 , Giovanni LANDONI 1,3*
}

${ }^{1}$ Department of Anesthesia and Intensive Care, San Raffaele Hospital IRCCS, Vita-Salute San Raffaele University, Milan, Italy; ${ }^{2}$ Károly Rácz School of PhD Studies, Semmelweis University, Budapest, Hungary; ${ }^{3}$ Vita-Salute San Raffaele University, Milan, Italy; ${ }^{4}$ Department of Anesthesiology and Pain Medicine, Ilsan Paik Hospital, Inje University, Goyang, South Korea; 'Division of Anesthesiology, Department of Anesthesiology, Pharmacology, Intensive Care, and Emergency Medicine, Geneva University Hospital, Geneva, Switzerland; 'Department of Medico-Surgical Sciences and Biotechnologies, Sapienza University, Rome, Italy; ${ }^{7}$ Mediterranea Cardiocentro, Naples, Italy

*Corresponding author: Giovanni Landoni, Department of Anesthesia and Intensive Care, IRCCS San Raffaele Scientific Institute, Via Olgettina 60, 20132 Milan, Italy. E-mail: landoni.giovanni@hsr.it

\section{A B S T R A C T}

INTRODUCTION: Several high quality randomized controlled studies were recently published on non-vitamin K oral anticoagulants (NOACs) in patients with or at risk for coronary artery (CAD) or peripheral artery disease (PAD). While a reduction on cardiovascular event is known and an increase in moderate bleeding is expected, the effect of this strategy on survival is currently unknown. Accordingly, we performed a comprehensive systematic review and meta-analysis of randomized controlled trials to investigate the effect of NOAC on survival.

EVIDENCE ACQUISITION: We searched Pubmed, EMBASE, Cochrane Central Register, and Clinicaltrials.gov (last updated March $31^{\text {th }}$ 2019). The primary endpoint was all-cause mortality at the longest reported follow-up. Coprimary endpoint was major bleeding according to the International Society on Thrombosis and Hemostasis (ISTH) criterion. EVIDENCE SYNTHESIS: We included ten randomized controlled trials comparing NOACs versus control treatment (placebo, single platelet or dual antiplatelet therapy) enrolling 66665 patients with or at risk for CAD or PAD. NOACs were associated with a decreased risk of mortality (825/41655 [4.4\%] versus 405/25010 [5.6\%] RR 0.93 [95\% CI: 0.871.00], $\mathrm{P}=0.04$ ), and an increased risk for major bleeding (RR 1.62 [95\% CI: 1.23-2.13], $\mathrm{P}=0.0005$ ) when compared to control. Findings were robust to trial sequential, subgroup, and sensitivity analyses. Low doses NOACs were associated with a reduced mortality when compared to standard dose NOACs.

CONCLUSIONS: NOACs reduced all-cause mortality in patients with or at risk for CAD or PAD, even though they increased the risk of major bleeding. Future studies regarding the best doses of NOACs are warranted.

(Cite this article as: Nagy A, Kim JH, Jeong ME, Heo MH, Putzu A, Belletti A, et al. Non-vitamin K oral anticoagulants for coronary or peripheral artery disease: a systematic review and meta-analysis of mortality and major bleeding. Minerva Cardioangiol 2019;67:000-000. DOI: 10.23736/S0026-4725.19.05043-6)

KEY WORDS: Mortality; Coronary artery disease; Peripheral arterial disease.

\section{Introduction}

$\mathrm{C}$ Yardiovascular diseases are one of the leading causes of morbidity and mortality worldwide with coronary artery $(\mathrm{CAD})$ and pe- ripheral artery diseases (PAD) representing the main burden for patients and national health systems. ${ }^{1}$ Non-vitamin $\mathrm{K}$ antagonist oral anticoagulants (NOAC) were developed for being at least as effective as traditional anticoagu- 
lants, with a more practical profile, such as oral administration with no need for routine monitoring or dose adjustment. NOACs are factor $\mathrm{Xa}$ or direct thrombin inhibitors. Ximelagatran was the first one, had limited success, but set the stage for the four widely approved and used NOACs: dabigatran, rivaroxaban, apixaban, and edoxaban. Guidelines are already including NOACs in the prevention of stroke in atrial fibrillation (except for the patients with mechanical prosthetic valves, or moderate to severe mitral stenosis), ${ }^{2}$ in the prevention or treatment of venous thromboembolism (VTE) after elective total hip or knee replacement surgery or in case of recurrent VTE. ${ }^{2,} 3$ Atherosclerosis is the common underlying pathophysiology in stable or unstable CAD or PAD. ${ }^{1}$ An eroded or ruptured plaque can activate both platelet aggregation and the coagulation cascade, leading to a thrombus or embolism. ${ }^{1}$ Unsurprisingly, atherosclerosis is associated with a high risk of cardiovascular adverse events and death. Aspirin inhibits platelet aggregation, reduces vascular events risk and mortality and is therefore widely used in primary and secondary cardiovascular prevention. 1, 4, 5 Additional P2Y12 inhibitor treatment offers a better survival in patients with recent acute myocardial infarction. ${ }^{4}$ However, despite the single or dual antiplatelet therapy, the number of new or recurrent cardiovascular adverse events including death is considerably high. ${ }^{6}$ Of note, there is no recommendation in guidelines (e.g. American Heart Association, European Society of Cardiology) against or towards the use of NOACs in this patient population. Published meta-analyses compared NOACs to vitamin $\mathrm{K}$ antagonist drugs in atrial fibrillation, ${ }^{7-9}$ investigated NOACs in addition to single or dual antiplatelet therapy in acute coronary syndrome (ACS), ${ }^{10}$ focused on patients with ischemic heart disease ${ }^{11}$ and explored the role of Rivaroxaban in CAD. ${ }^{12}$ Results are contradictory and there is lack of a comprehensive meta-analysis on this important field. The aim of our systematic review and meta-analysis is to evaluate the effect of NOACs versus placebo or single or dual antiplatelet therapy on survival and bleeding in patients with or at risk for CAD or PAD.

\section{Evidence acquisition}

We performed a systematic review and metaanalysis of randomized controlled trials (RCTs), according to the Cochrane methodology ${ }^{13}$ and preferred reporting items for systematic reviews and meta-analyses PRISMA. ${ }^{14}$

\section{Search strategy and selection criteria}

Two trained investigators (AN, JHK) independently searched Pubmed, EMBASE, and the Cochrane Central Register of clinical trials together with Clinicaltrials.gov for recently completed but not published studies, dated up to March $31^{\text {th }}, 2019$. The search strategies for PubMed and EMBASE are available in the Supplementary Digital Material 1 (Supplementary Text File 1). The search strategies were designed to find any RCTs ever published with the utilization of NOACs in patients with or at risk for CAD or PAD. We checked the references of included studies to identify more eligible RCTs. No language restrictions were added. Articles were first screened as title and abstract and, if met the inclusion criteria, retrieved as a complete manuscript. Eligible studies had to meet the following PICOS criteria: Population: adult patients with the diagnosis or at high risk of CAD or PAD; Interventions: administration of NOACs and antiplatelet drugs or NOACs alone; Comparison intervention: placebo or single or dual antiplatelet therapy; Outcome: survival, or occurrence of clinically significant bleeding; Study design: randomized controlled trials. Disagreements between the two investigators about the eligibility of the article were solved by a third expert author.

\section{Data analysis}

Two trained authors (AN, JHK) separately gathered the baseline characteristics, outcome data, and additional relevant information from the selected studies. The primary endpoint was all cause of mortality at the longest reported followup. Coprimary endpoint was major bleeding according to the International Society on Thrombosis and Hemostasis (ISTH) criterion. ${ }^{15}$ Secondary endpoints were the rate of cardiovascular death, acute myocardial infarction, hemorrhagic and non-hemorrhagic stroke, fatal bleeding, in- 
tracranial bleeding, gastrointestinal bleeding, minor bleeding and need for hospital admission. In case of missing data of an outcome of interest, we contacted the corresponding authors. For the evaluation of the included trial risk of bias, we used the Cochrane methodology. ${ }^{13}$ We assessed each study separately according to Cochrane's seven items as low, high or unclear risk of bias. We performed our analysis with RevMan 5.3. software (Review Manager, The Nordic Cochrane Centre, The Cochrane Collaboration, Copenhagen, Denmark) and Stata version 14.1 (StataCorp., College station, TX, USA). For dichotomous outcomes in primary and secondary endpoints, individual and pooled risk ratios were calculated via the Mantel-Haenszel method. We presented calculated risk ratio (RR) with $95 \%$ confidence intervals $(\mathrm{CI})$. All reported $\mathrm{P}$ values are two-sided and the values equal or less than 0.05 were counted as significant. Heterogeneity among included studies was analyzed with Cochrane Q statistics and quantified with $\mathrm{I}^{2}$. Fixed effect model was performed to create meta-analysis in the absence of significant heterogeneity, defined as $\mathrm{P}$ value $>0.10$ and $\mathrm{I}^{2}<40 \%$. 13 We employed a random-effect model in case of significant heterogeneity. We performed a fixed-effects trial sequential analysis (TSA) with the intent of maintaining an overall $5 \%$ risk of type I error and a $20 \%$ risk of type II error, at a power of $80 \%$. We assumed a relative risk reduction of $15 \%$ and derived the control event proportion from the dataset. The resulting required information size was further diversity $\left(\mathrm{D}^{2}\right)$-adjusted. In the case of $\mathrm{D}^{2}=0$, we performed a sensitivity analysis assuming a $\mathrm{D}^{2}=25 \%$. The TSA Viewer software was used to perform TSA (TSA Viewer [Computer program], version 0.9.5.5 Beta, Copenhagen Trial Unit, Centre for Clinical Intervention Research, Rigshospitalet, 2016).

Based on Cochrane methodology, we performed further subgroup analyses. In particular, we investigated the effect of low dose NOACs and standard dose NOACs. Subgroup differences were tested using $\chi^{2}$ statistics. We considered the following $\mathrm{mg}$ /day dosages as low dose: rivaroxaban $5 \mathrm{mg}$ /day; apixaban $5 \mathrm{mg}$ /day; dabigatran 100-150 mg/day. The following were considered standard dose: rivaroxaban $10 \mathrm{mg} /$ day; apixaban $10 \mathrm{mg} /$ day; dabigatran $220 \mathrm{mg} /$ day. ${ }^{16,} 17$ These drugs are used in various clinical indications, therefore it was hard to create a threshold value between the two subgroups. We created these categories considering the dosages of the included studies and the international recommendations.

Our study was preregistered in PROSPERO (reg. No. 2019-CRD42019119717).

\section{Evidence synthesis}

Our search strategy identified 761 records (Figure 1). Major exclusion papers are presented in Supplementary Digital Material 2 (Supplementary Table I). Ten studies were eligible for inclusion into the final analyses (Table I). $4-6,18-24$

In summary, the data of $66,665(41,655$ experimental and 25,010 control group) patients were included. The most commonly studied study drug was rivaroxaban ( 5 out of 10 studies $4,6,20,21,24$ ) followed by apixaban ( 3 studies $18,19,22)$, and dabigatran (2 studies $\left.^{5}, 23\right)$. The studied settings were recent ACS in 7 articles ${ }^{4}, 18-23$ and were stable CAD or PAD, ${ }^{6}$ myocardial injury after non-cardiac surgery (MINS), ${ }^{5}$ and heart failure with $\mathrm{CAD}^{24}$ in each other articles. Placebo was used as control treatment in 8 studies,, , 18-24 the

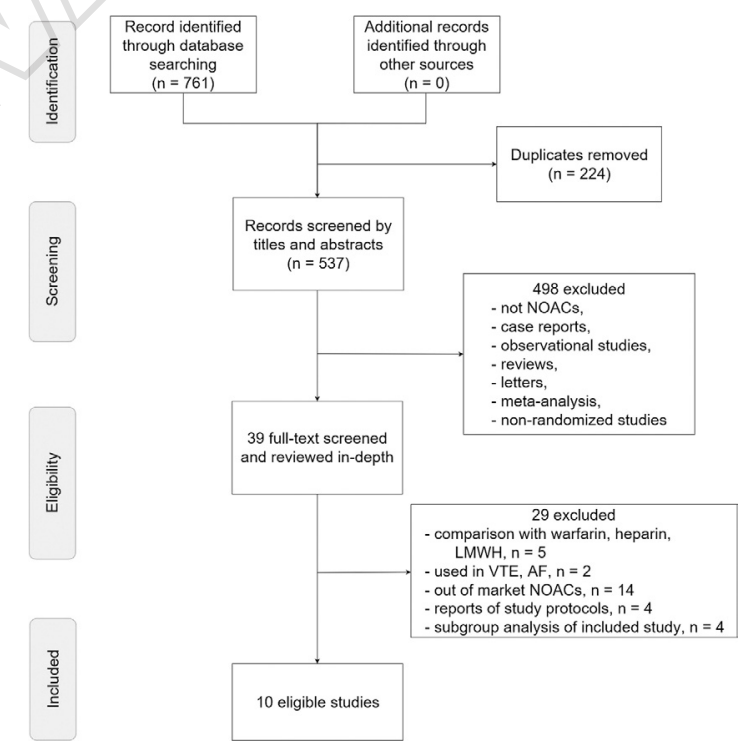

Figure 1.-Flow chart of study selection.

NOACs: non-vitamin K oral anticoagulants; LMWH: low molecular weight heparin; VTE: venous thromboembolism. 
TABLE I.-Characteristics of included studies.

\begin{tabular}{|c|c|c|c|c|}
\hline & Study abbreviation & Population & Study period & Patient etiology \\
\hline Alexander et al. (2009) ${ }^{18}$ & APPRAISE & 1691 & 2006.05-2007.10 & Recent ACS with high risk factors \\
\hline Alexander et al. $(2011)^{19}$ & APPRAISE-2 & 7392 & 2009.03-2010.11 & Recent ACS with high risk factors \\
\hline Devereaux et al. $(2018)^{5}$ & MANAGE trial & 1754 & 2013.01-2017.07 & Myocardial injury after non-cardiac surgery \\
\hline Eikelboom et al. $(2017)^{6}$ & COMPASS trial & 27,395 & 2013.03-2016.05 & Stable atherosclerotic vascular disease \\
\hline Mega et al. $(2009)^{20}$ & ATLAS ACS-TIMI 46 & 3491 & 2006.11-2008.09 & Recent ACS \\
\hline Mega et al. $(2012)^{21}$ & ATLAS ACS-TIMI 51 & 15,526 & 2008.11-2011.09 & Recent ACS \\
\hline Ogawa et al. $(2013)^{22}$ & APPRAISE-Japan & 149 & 2009.04-2010.11 & Recent ACS with high risk factors \\
\hline Ohman et al. $(2017)^{4}$ & GEMINI-ACS-1 & 3037 & 2015.04-2016.10 & After ACS \\
\hline Oldgren et al. $(2011)^{23}$ & RE-DEEM & 1861 & 2008.03-2009.10 & $\begin{array}{l}\text { Recent MI, and at high risk of new } \\
\text { ischemia }\end{array}$ \\
\hline Zannad et al. $(2018)^{24}$ & COMMANDER HF & 5022 & (2) & $\begin{array}{l}\text { Recent worsening heart failure, reduced } \mathrm{EF} \text {, } \\
\mathrm{CAD} \text {, and no } \mathrm{AF}\end{array}$ \\
\hline
\end{tabular}

NOAC: non-vitamin K oral anticoagulant; ACS: acute coronary syndrome; EF: ejection fraction; CAD: coronary artery disease; AF: atrial fibrillation; APX: apixaban; RIV: rivaroxaban; ASA: acetyl salicylic acid; DABI: dabigatran.

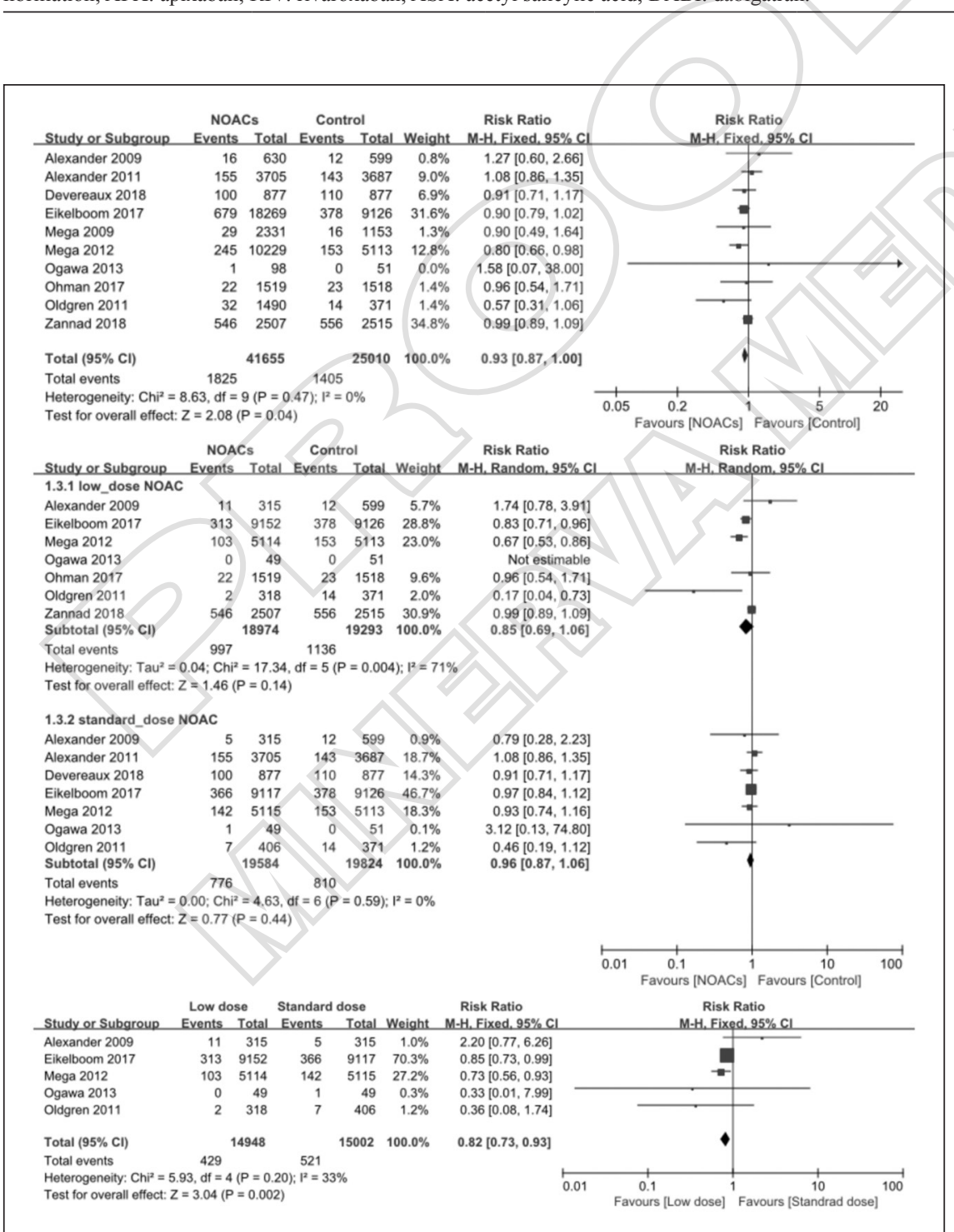

Figure 2.-Forest plots of all-cause mortality at the longest follow-up. 4-6, 18-24 NOACs: non-vitamin K oral anticoagulants. 


\begin{tabular}{|c|c|c|c|}
\hline Type of NOAC & Study groups & NOAC patients & Control atients \\
\hline APX & 5 mg APX / 10 mg APX / 20 mg APX / Placebo & 630 & 599 \\
\hline APX & $10 \mathrm{mg}$ (5 mg in decreased renal function) APX / Placebo & 3705 & 3687 \\
\hline DABI & $220 \mathrm{mg}$ DABI / Placebo & 877 & 877 \\
\hline RIV & $5 \mathrm{mg}$ RIV + ASA / $10 \mathrm{mg}$ RIV / Placebo + ASA & 18269 & 9126 \\
\hline RIV & 5, 10, $20 \mathrm{mg}$ RIV / 5, 10, 15, $20 \mathrm{mg}$ RIV + thienopyridine / Placebo & 2331 & 1153 \\
\hline RIV & 5 mg RIV / 10 mg RIV / Placebo & 10229 & 5113 \\
\hline APX & $5 \mathrm{mg}$ APX / $10 \mathrm{mg}$ APX / Placebo & 98 & 51 \\
\hline RIV & 5 mg RIV + P2Y12inhibitor / ASA + P2Y12inhibitor & 1519 & 1518 \\
\hline DABI & $100 \mathrm{mg}$ DABI / $150 \mathrm{mg}$ DABI / $220 \mathrm{mg}$ DABI / $300 \mathrm{mg}$ DABI / Placebo & 1490 & 371 \\
\hline RIV & 5 mg RIV / Placebo & & 2515 \\
\hline
\end{tabular}

remaining two $0^{4,6}$ used aspirin. Standard medication of artery diseases was maintained during the study period, therefore none of the comparator groups were totally free of antiplatelet (Aspirin and/or P2Y12 antagonists) treatment. Only one study ${ }^{6}$ had an experimental arm without administration of antiplatelet agents. Eight studies $^{4,6,18,20-24}$ used a low dose and 8 studies $5,6,18-23$ used a standard dose of NOAC. All studies had low risk of bias (Supplementary Digital Material 3: Supplementary Table II).

\section{Mortality}

Overall, administration of NOACs significantly decreased the risk of death compared to control treatment (10 RCT, 1825/41,655 [4.4\%] NOAC, $1405 / 25,010$ [5.6\%] control, N. $=66,665, R R$ 0.93 [95\% CI: $0.87-1.00], \mathrm{P}=0.04, \mathrm{I}=0 \%$ ) (Figure 2). ${ }^{4-6,}{ }^{18-24}$ Final analysis is conclusive according to TSA (Supplementary Digital Material 4: Supplementary Figure 1).

Overall, we found significant difference in the comparison of low dose versus standard dose of NOACs (5 RCT, 429/14,948 [2.9\%] low dose, $521 / 15002[3.5 \%]$ standard dose, N. $=29,950, \mathrm{RR}$ 0.82 [0.73-0.93], $\left.\mathrm{P}=0.002, \mathrm{I}^{2}=33 \%\right)$. Sequential removing each trial did not change magnitude and direction of treatment effect (lowest RR 0.81 [95\% CI: 0.71-0.92], $\mathrm{P}=0.001, \mathrm{I}=0 \%$ ) with the removal of Alexander $e t$ al. and (highest RR 0.86 [95\% CI: 0.74-0.99], $\mathrm{P}=0.04, \mathrm{I}^{2}=35 \%$ ) with the removal of Mega et al. Subgroup analysis by low dose and standard dose of NOACs found no difference between treatment and control in case of low doses (7 RCT, 997/18974 [5.3\%] NOAC, $1136 / 19293$ [5.9\%] control, N. $=38267$, RR 0.85 [95\% CI: $0.69-1.06], \mathrm{P}=0.14, \mathrm{I}^{2}=71 \%$ ) and also in case of standard doses (7 RCT, 776/19,584 [4.0\%] NOAC, 810/19,824 [4.1\%] control, $\mathrm{N} .=39,408$, RR $0.96 \quad$ [95\% CI: $0.87-1.06]$, $\mathrm{P}=0.44, \mathrm{I}^{2}=0 \%$ ) (Figure 2).

\section{Major bleeding}

Patients treated with NOACs had an increased risk of major bleeding according to ISTH when compared to control group (8 RCT, 681/29,095 [2.3\%] NOAC, 327/18,744 [1.7\%] control, $\mathrm{N} .=47,839, \quad \mathrm{RR} 1.62 \quad[95 \%$ CI: $1.23-2.13]$, $\mathrm{P}=0.0005, \mathrm{I}^{2}=60 \%$ ) (Figure 3). ${ }^{4-6,18-24}$ TSA analysis revealed this inconclusive (Supplementary Digital Material 5: Supplementary Figure 2).

Comparison of different doses of NOAC revealed, that standard dose significantly increased the risk of major bleeding (4 RCT, 216/10,253 [2.1\%] low dose, 271/9887 [2.7\%] standard dose, $\mathrm{N} .=20,140$, RR 0.78 [95\% CI: 0.66-0.93], $\mathrm{P}=0.007, \mathrm{I}^{2}=6 \%$ ) (Supplementary Digital Material 6: Supplementary Table III). Subgroup analysis found that, both low dose (6 RCT, 329/14279 [2.3\%] NOAC, 244/14180 [1.7\%] control, $\mathrm{N} .=28,459$, RR $1.35 \quad$ [95\% CI: $1.15-1.59$ ], $\left.\mathrm{P}=0.0003, \mathrm{I}^{2}=0 \%\right)$ and standard dose (6 RCT, 428/14,469 [3.0\%] NOAC, 260/14711 [1.8\%] control, N. $=29180$, RR 1.66 [95\% CI: 1.43-1.93], $\mathrm{P}<0.0001, \mathrm{I} 2=38 \%$ ) increased the risk of major bleeding compare to control treatment (Table II). 


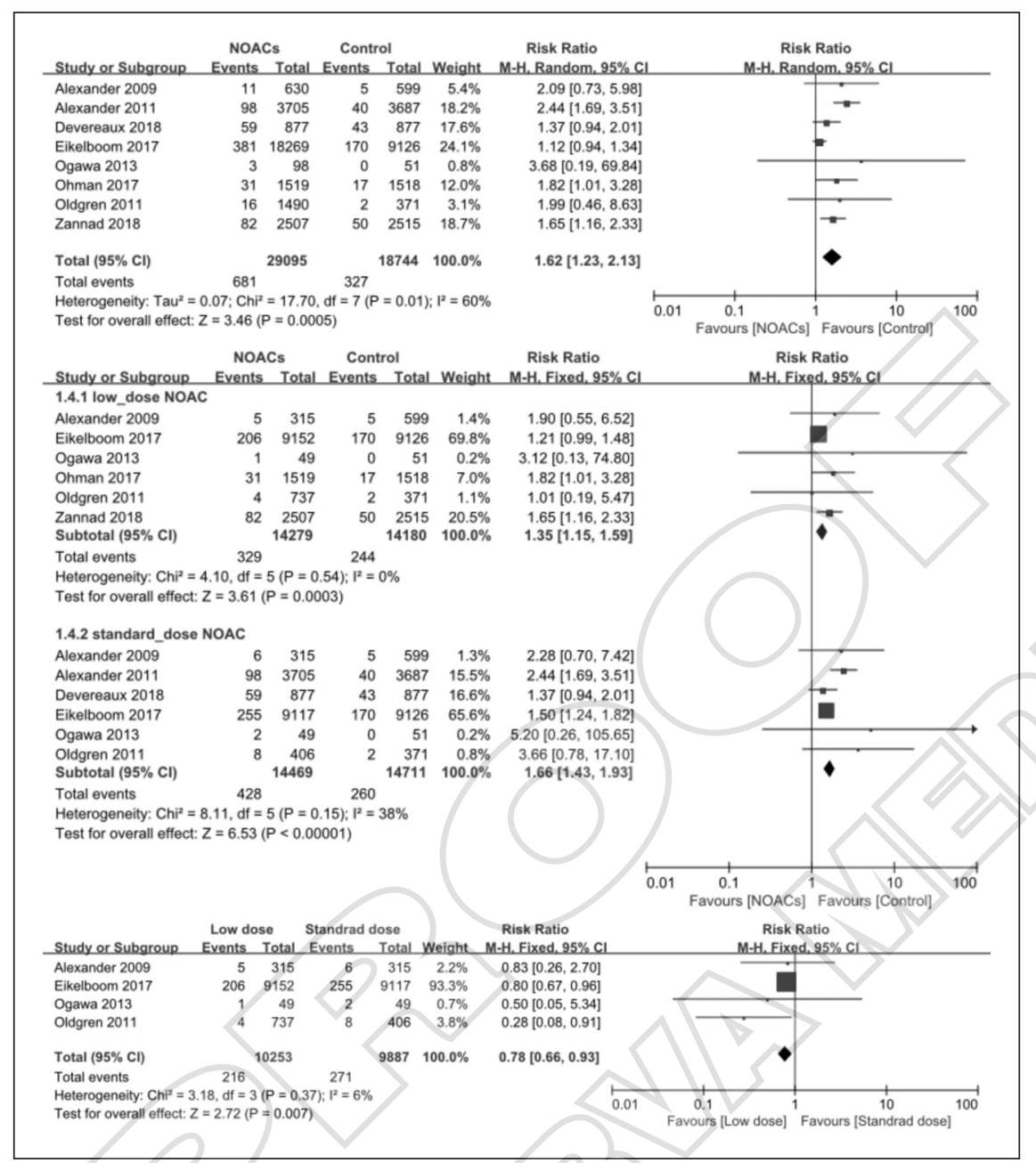

Figure 3.-Forest plots of major bleeding according to International Society on Thrombosis and Hemostasis (ISTH). ${ }^{4-6,18-24}$

NOACs: non-vitamin K oral anticoagulants.

\section{Secondary outcomes}

Meta-analyses of secondary outcomes revealed the following results. The risk rate of cardiovascular death, acute myocardial infarction, and stroke (hemorrhagic and non-hemorrhagic) was significantly higher in the control group compared to NOAC treatment group. The risk of intracranial bleeding, gastrointestinal bleeding, and minor bleeding was increased among patients treated with NOACs compare to control (Table II, Supplementary Digital Material 7: Supplementary Figure 3).

Sensitivity analysis performed by sequential removal of each included study did not change the magnitude and direction of the overall results and are reported in Supplementary Digi- tal Material 8 (Supplementary Table IV). Egger's test revealed publication bias in the minor bleeding analysis $(\mathrm{P}=0.035)$ (Table II, Supplementary Digital Material 9: Supplementary Figure 4), the remaining analyses are free of publication bias (Table II, Supplementary Digital Material 9).

\section{Limitations of the study}

One limitation of our study is that we included studies which used a different definition of major bleeding. The majority of studies used ISTH definition of major bleeding, but some of the studies used TIMI definition 20,21 and after unsuccessful attempts to contact the authors we excluded those studies from this outcome anal- 
TABLE II.-Summary of findings (overall and subgroup) and Egger's Test.

\begin{tabular}{|c|c|c|c|c|c|c|c|c|c|c|}
\hline \multirow{2}{*}{ Outcome of interest } & \multirow{2}{*}{$\begin{array}{l}\text { Number } \\
\text { of } \\
\text { included } \\
\text { trials }\end{array}$} & \multirow{2}{*}{$\begin{array}{l}\text { Participants, } \\
\text { N. }\end{array}$} & \multicolumn{2}{|c|}{ NOAC group } & \multicolumn{2}{|c|}{ Control group } & \multirow{2}{*}{$\begin{array}{l}\text { Risk ratio } \\
(95 \% \mathrm{CI})\end{array}$} & \multirow{2}{*}{$\begin{array}{c}\mathrm{P} \text { for } \\
\text { significance }\end{array}$} & \multirow{2}{*}{$\begin{array}{l}\mathrm{I}^{2} \\
(\%)\end{array}$} & \multirow{2}{*}{$\begin{array}{c}\text { Egger' } \\
\text { test } P \\
\text { value }\end{array}$} \\
\hline & & & Events & Total & Events & Total & & & & \\
\hline $\begin{array}{l}\text { All-cause mortality at } \\
\text { longest follow-up }\end{array}$ & 10 & 66,665 & 1825 & 41,655 & 1405 & 25,010 & $0.93(0.87-1.00)$ & 0.04 & 0 & 0.919 \\
\hline Low dose & 7 & 38,267 & 997 & 18,974 & 1136 & 19,293 & $0.85(0.69-1.06)$ & 0.14 & 71 & \\
\hline Standard dose & 7 & 39,408 & 776 & 19,584 & 810 & 19,824 & $0.96(0.87-1.06)$ & 0.44 & 0 & \\
\hline Major bleeding (ISTH) & 8 & 47,839 & 681 & 29,095 & 327 & 18,744 & $1.62(1.23-2.13)$ & 0.001 & 60 & 0.113 \\
\hline Low dose & 6 & 28,459 & 329 & 14,279 & 244 & 14,180 & $1.35(1.15-1.59)$ & $<0.001$ & 0 & \\
\hline Standard dose & 6 & 29,180 & 428 & 14,469 & 260 & 14711 & $1.66(1.43-1.93)$ & $<0.001$ & 38 & \\
\hline Cardiovascular death & 9 & 63,181 & 1251 & 39,324 & 1032 & 23,857 & $0.90(0.84-0.99)$ & 0.01 & 0 & 0.668 \\
\hline Low dose & 7 & 38,686 & 754 & 19,393 & 859 & 19,293 & $0.87(0.71-1.06)$ & 0.18 & 58 & \\
\hline Standard dose & 7 & 39,408 & 494 & 19,584 & 539 & 19,824 & $0.92(0.82-1.04)$ & 0.19 & 0 & \\
\hline $\begin{array}{l}\text { Acute myocardial } \\
\text { infarction }\end{array}$ & 10 & 66,665 & 1227 & 41,655 & 905 & 25,010 & $0.88(0.80-0.96)$ & 0.003 & & \\
\hline Low dose & 7 & 38,686 & 561 & 19,393 & 624 & 19,293 & $0.90(0.80-1.01)$ & 0.07 & 0 & \\
\hline Standard dose & 7 & 39,408 & 591 & 19,584 & 694 & 19,824 & $0.86(0.77-0.96)$ & 0.006 & 0 & \\
\hline Stroke & 10 & 66,665 & 391 & 41,655 & 327 & 25,010 & $0.69(0.53-0.91)$ & 0.008 & 44 & 0.146 \\
\hline Low dose & 3 & 19,486 & 84 & 9938 & 146 & 9548 & $0.57(0.44-0.74)$ & 0.001 & 0 & \\
\hline Standard dose & 5 & 31,102 & 155 & 15,564 & 197 & 15,538 & $0.79(0.64-0.97)$ & 0.02 & 22 & \\
\hline Fatal bleeding & 7 & 60,198 & 67 & 37,817 & 29 & 22,381 & $1.37(0.89-2.11)$ & 0.15 & 0 & 0.529 \\
\hline Low dose & 6 & 37,772 & 32 & 19,078 & 29 & 18,694 & $1.07(0.64-1.77)$ & 0.80 & 0 & \\
\hline Standard dose & 6 & 39,961 & 44 & 19,269 & 35 & 20,692 & $1.63(0.68-3.91)$ & 0.28 & 60 & \\
\hline Intracranial bleeding & 7 & 58,010 & 120 & 36,719 & 35 & 21,291 & $1.91(1.31-2.77)$ & 0.001 & 0 & 0.327 \\
\hline Low dose & 5 & 33,564 & 43 & 16,837 & 29 & 16,727 & $1.47(0.92-2.35)$ & 0.10 & 18 & \\
\hline Standard dose & 6 & 40,455 & 77 & 19,535 & 35 & 20,920 & $2.20(1.48-3.28)$ & $<0.001$ & 0 & \\
\hline Gastrointestinal bleeding & 5 & 32,388 & 326 & 21,364 & 83 & 11,024 & $2.00(1.57-2.54)$ & $<0.001$ & 0 & 0.507 \\
\hline Low dose & 4 & 20,400 & 179 & 10,253 & 77 & 10,147 & $2.53(1.31-4.91)$ & 0.006 & 54 & \\
\hline Standard dose & & 21,788 & 136 & 10,764 & 83 & 11,024 & $1.97(1.25-3.09)$ & 0.003 & 31 & \\
\hline Minor bleeding & & 60,414 & 2080 & 38,518 & 663 & 21,896 & $1.63(1.49-1.77)$ & $<0.001$ & 21 & 0.035 \\
\hline Low dose & & 32,750 & 984 & 16,571 & 566 & 16,179 & $1.66(1.50-1.83)$ & $<0.001$ & 0 & \\
\hline Standard dose & 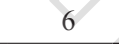 & 38,494 & 1037 & 19,269 & 657 & 19,225 & $1.77(1.43-2.19)$ & $<0.001$ & 56 & \\
\hline
\end{tabular}

NOAC: non-vitamin K oral anticoagulant; ISTH: International Society on Thrombosis and Hemostasis.

ysis. Patients were at different risk profiles in the included trials, since we chose to involve a wide spectrum of diseases (although they shared same pathogenesis) in our population. The comprehensive range of disease could cause the significant heterogeneity among the results of the trials. Two further limitation can be the distinction of different NOAC doses with creating low and standard dose and also the comparability of different type of NOACs with low and standard doses. Different concomitant antiplatelet therapies were used in the included studies, therefore, our population is heterogenic in that aspect. The recruiting time of the first and last included study were more than 10 years apart, which could have caused changes in many aspects. Another possible limitation of all the studies included in this meta-analysis is that they were all supported by pharmaceutical companies. Furthermore, no study used competing risk models (CRM) for the main analysis, and we also extracted raw event estimates. Therefore, CRM was not applied to our analysis either. While heterogeneity was mild for main comparative analyses, it varied substantially depending on outcome or control group, with more severe heterogeneity when appraising endpoints with different definitions. Finally, no multivariate meta-analysis method was applied in our work.

\section{Conclusions}

Our results show that NOACs decrease all-cause mortality in $\mathrm{CAD}$ and $\mathrm{PAD}$, but they also increase the risk of major bleeding by ISTH criteria. Results were confirmed in most sub-analyses and sensitivity analyses.

The only recent meta-analysis of NOACs 
which included patients similar to those of our meta-analysis was limited to only one NOAC agent (four trials on rivaroxaban were included). ${ }^{12}$ As far as we know, our study is the first which encompasses all the NOACs into the analysis. We included all the studies performed over more than ten years, gathered all the reports on all marketed NOACs, even including sensitivity analyses with those which are currently not on the market and had results showing similar magnitude and direction that the main analyses (Supplementary Digital Material 10: Supplementary Table V). Studies with out of market NOACs are indicated in the Supplementary Digital Material 2.

All the studies we included $(66,665$ patients overall) were high-quality RCTs, and at low risk of bias. Previous meta-analyses of NOACs usually included only patients with atrial fibrillation or venous thromboembolism (VTE), or belonging to a specific age population.7, 25-27 Cohen et al. performed a systematic review and metaanalysis of NOACs in VTE, reporting that the risk of VTE or VTE-related death was lower in NOACs and warfarin INR 2.0-3.0 when compared with aspirin. ${ }^{25}$ Hulle et al. also compared NOACs with VKAs in VTE and concluded that the efficacy of NOACs was comparable to VKA and that the risk of bleeding complication was reduced. ${ }^{26}$ Zelniker et al. compared NOACs with warfarin in patients with atrial fibrillation, to find out if there was effect modification by CAD status. ${ }^{7}$ The effect of NOACs was beneficial compared to warfarin and was not different by the presence or absence of the CAD. Sardar et al. compared NOACs with conventional treatment (Warfarin, aspirin, enoxaparin, VKA, or placebo) in patients aged 75 and older with various diseases, and reported that NOACs did not cause excessive bleeding and were associated with equal or greater efficacy than conventional treatment. ${ }^{27}$

These favourable results of NOACs might be caused by possible merits over other anticoagulants. First, NOACs target specific factors in the coagulation cascade (either factor Xa or thrombin), unlike warfarin and VKAs. ${ }^{28}$ Second, NOACs do not completely inhibit the target protease. The inhibition of thrombin molecules increased proportionally as the concentration of NOACs increases. If more thrombin is generated, the level of free (active) thrombin will increase at any given concentration of NOACs. Thus, if there are sufficiently strong procoagulant stimulus, the inhibitory effect could be overcome. ${ }^{28}$ This might be the reason why a lower incidence of intracranial bleeding was reported with some NOACs than VKAs in several studies. ${ }^{29-31}$ However, the overall clinical effect of this property seems to be difficult to predict. 28

In our analysis, NOACs decreased all-cause mortality even though they increased major bleeding. Similarly, the effects of NOACs on secondary endpoints showed both favourable and unfavourable results. Effects of NOAC on bleeding seems to be dose-dependent, according to the subgroup analysis of low dose versus standard dose in major bleeding and intracranial haemorrhage. When comparing low dose NOACs versus standard dose NOACs we found that low doses were associated with reduced mortality, reduced major bleeding, and stroke. Using a low dose of NOACs in these setting seems reasonable according to the finding of this study but considering that there is still debate about dosing in other settings, ${ }^{32-34}$ we could not conclude which dosage is beneficial. Maybe there shall be a "Goldilocks" dose which won't increase the risk of bleeding, although still reduces mortality. Or there may be a need for different doses for a different population (i.e., standard dose NOAC for AMI patients and low dose for other patients).

We did not want to include a comparison of warfarin with NOACs, because warfarin was used almost exclusively in atrial fibrillation which was not included in our current research. However, warfarin might have a role in CAD or PAD, like NOACs, and may have some advantages compared to NOACs. The beneficial effects of warfarin in cardiovascular disease were previously reported. ${ }^{35-37}$ Also, it has cheap, easy to get, well-known antidotes (vitamin K, fresh frozen plasma and coagulation factors concentrates). In contrast, the antidotes for NOACs are not available, recently approved, or very expensive. ${ }^{38-40}$ When bleeding occurs, the availability of an antidote may be important to the outcome.

In conclusion, NOACs reduced all-cause mor- 
tality in patients with or at risk for CAD or PAD, even though it increased the risk of major bleeding. Future study regarding the best doses of NO$\mathrm{ACs}$ is warranted.

\section{References}

1. Connolly SJ, Eikelboom JW, Bosch J, Dagenais G, Dyal $\mathrm{L}$, Lanas $\mathrm{F}$, et al.; COMPASS investigators. Rivaroxaban with or without aspirin in patients with stable coronary artery disease: an international, randomised, double-blind, placebocontrolled trial. Lancet 2018;391:205-18.

2. Huynh K. Milestone 10: era of the NOACs. Nat Rev Cardiol 2017. ]Epub ahead of print]

3. Cully M. Milestone 9: ximelagatran sets the stage for NOACs. Nat Rev Cardiol 2017. ]Epub ahead of print]

4. Ohman EM, Roe MT, Steg PG, James SK, Povsic TJ, White $\mathrm{J}$, et al. Clinically significant bleeding with low-dose rivaroxaban versus aspirin, in addition to $\mathrm{P} 2 \mathrm{Y} 12$ inhibition, in acute coronary syndromes (GEMINI-ACS-1): a double-blind, multicentre, randomised trial. Lancet 2017;389:1799-808.

5. Devereaux PJ, Duceppe E, Guyatt G, Tandon V, Rodseth $\mathrm{R}$, Biccard BM, et al.; MANAGE Investigators. Dabigatran in patients with myocardial injury after non-cardiac surgery (MANAGE): an international, randomised, placebo-controlled trial. Lancet 2018;391:2325-34.

6. Eikelboom JW, Connolly SJ, Bosch J, Dagenais GR, Hart RG, Shestakovska O, et al.; COMPASS Investigators. Rivaroxaban with or without Aspirin in Stable Cardiovascular Disease. N Engl J Med 2017;377:1319-30.

7. Zelniker TA, Ruff CT, Antman EM, Giugliano RP. The efficacy and safety of non-vitamin $\mathrm{K}$ antagonist oral anticoagulants in patients with atrial fibrillation and coronary artery disease: A meta-analysis of randomized trials. Eur Heart J Acute Cardiovasc Care 2018;2048872618796990.

8. Bennaghmouch N, de Veer AJ, Bode K, Mahmoodi BK, Dewilde WJ, Lip GY, et al. Efficacy and Safety of the Use of Non-Vitamin K Antagonist Oral Anticoagulants in Patients With Nonvalvular Atrial Fibrillation and Concomitant Aspirin Therapy: A Meta-Analysis of Randomized Trials. Circulation 2018;137:1117-29.

9. Wang KL, Lopes RD, Patel MR, Büller HR, Tan DS, Chiang $\mathrm{CE}$, et al. Efficacy and safety of reduced-dose non-vitamin $\mathrm{K}$ antagonist oral anticoagulants in patients with atrial fibrillation: a meta-analysis of randomized controlled trials. Eur Heart J 2019;40:1492-500.

10. Khan SU, Arshad A, Riaz IB, Talluri S, Nasir F, Kaluski E. Meta-Analysis of the Safety and Efficacy of the Oral Anticoagulant Agents (Apixaban, Rivaroxaban, Dabigatran) in Patients With Acute Coronary Syndrome. Am J Cardiol 2018;121:301-7.

11. Fu L, Zhu W, Huang L, Hu J, Ma J, Lip GY, et al. Efficacy and Safety of the Use of Non-vitamin K Antagonist Oral Anticoagulants in Patients with Ischemic Heart Disease: A MetaAnalysis of Phase III Randomized Trials. Am J Cardiovasc Drugs 2019;19:37-47.

12. Yuan J. Efficacy and safety of adding rivaroxaban to the anti-platelet regimen in patients with coronary artery disease: a systematic review and meta-analysis of randomized controlled trials. BMC Pharmacol Toxicol 2018;19:19.

13. Higgins JP, Green S, editors. Cochrane Handbook for Systematic Reviews of Interventions Version 5.1.0 [updated
March 2011]. The Cochrane Collaboration; 2011 [Internet]. Available from: https://handbook-5-1.cochrane.org/ [cited 2019, Jun 30].

14. Moher D, Liberati A, Tetzlaff J, Altman DG; PRISMA Group. Preferred reporting items for systematic reviews and meta-analyses: the PRISMA statement. PLoS Med 2009;6:e1000097.

15. Schulman S, Angerås U, Bergqvist D, Eriksson B, Lassen MR, Fisher W; Subcommittee on Control of Anticoagulation of the Scientific and Standardization Committee of the International Society on Thrombosis and Haemostasis. Definition of major bleeding in clinical investigations of antihemostatic medicinal products in surgical patients. J Thromb Haemost 2010;8:202-4

16. Clinical Excellence Commission. 2017, Non-vitamin K Antagonist Oral Anticoagulant (NOAC) Guidelines, Updated July 2017. Sydney: Clinical Excellence Commission; 2017 [Internet]. Available from: http://www.cec.health.nsw.gov. au/ data/assets/pdf_file/0007/326419/noac_guidelines.pdf [cited 2019, Jun 31].

17. Steffel J, Verhamme P, Potpara TS, Albaladejo P, Antz M, Desteghe L, et al.; ESC Scientific Document Group. The 2018 European Heart Rhythm Association Practical Guide on the use of non-vitamin $\mathrm{K}$ antagonist oral anticoagulants in patients with atrial fibrillation: executive summary. Europace 2018;20:1231-42.

18. Alexander JH, Becker RC, Bhatt DL, Cools F, Crea F, Dellborg M, et al.; APPRAISE Steering Committee and Investigators. Apixaban, an oral, direct, selective factor Xa inhibitor, in combination with antiplatelet therapy after acute coronary syndrome: results of the Apixaban for Prevention of Acute Ischemic and Safety Events (APPRAISE) trial. Circulation 2009;119:2877-85

19. Alexander JH, Lopes RD, James S, Kilaru R, He Y, Mohan $\mathrm{P}$, et al.; APPRAISE-2 Investigators. Apixaban with antiplatelet therapy after acute coronary syndrome. N Engl J Med 2011;365:699-708

20. Mega JL, Braunwald E, Mohanavelu S, Burton P, Poulter $\mathrm{R}$, Misselwitz F, et al.; ATLAS ACS-TIMI 46 study group. Rivaroxaban versus placebo in patients with acute coronary syndromes (ATLAS ACS-TIMI 46): a randomised, doubleblind, phase II trial. Lancet 2009;374:29-38.

21. Mega JL, Braunwald E, Wiviott SD, Bassand JP, Bhatt DL, Bode C, et al.; ATLAS ACS 2-TIMI 51 Investigators. Rivaroxaban in patients with a recent acute coronary syndrome. N Engl J Med 2012;366:9-19.

22. Ogawa H, Goto S, Matsuzaki M, Hiro S, Shima D; APPRAISE-J investigators. Randomized, double-blind trial to evaluate the safety of apixaban with antiplatelet therapy after acute coronary syndrome in Japanese patients (APPRAISEJ). Circ J 2013;77:2341-8.

23. Oldgren J, Budaj A, Granger CB, Khder Y, Roberts J, Siegbahn A, et al.; RE-DEEM Investigators. Dabigatran vs. placebo in patients with acute coronary syndromes on dual antiplatelet therapy: a randomized, double-blind, phase II trial. Eur Heart J 2011;32:2781-9.

24. Zannad F, Anker SD, Byra WM, Cleland JG, Fu M, Gheorghiade $\mathrm{M}$, et al.; COMMANDER HF Investigators. Rivaroxaban in Patients with Heart Failure, Sinus Rhythm, and Coronary Disease. N Engl J Med 2018;379:1332-42.

25. Cohen AT, Hamilton M, Bird A, Mitchell SA, Li S, Horblyuk R, et al. Comparison of the Non-VKA Oral Anticoagulants Apixaban, Dabigatran, and Rivaroxaban in the Extended Treatment and Prevention of Venous Thromboembolism: Systematic Review and Network Meta-Analysis. PLoS One 2016;11:e0160064. 
26. van der Hulle T, Kooiman J, den Exter PL, Dekkers OM, Klok FA, Huisman MV. Effectiveness and safety of novel oral anticoagulants as compared with vitamin $\mathrm{K}$ antagonists in the treatment of acute symptomatic venous thromboembolism: a systematic review and meta-analysis. J Thromb Haemost 2014;12:320-8.

27. Sardar P, Chatterjee S, Chaudhari S, Lip GY. New oral anticoagulants in elderly adults: evidence from a meta-analysis of randomized trials. J Am Geriatr Soc 2014;62:857-64.

28. Hoffman M, Monroe DM. Impact of Non-Vitamin K Antagonist Oral Anticoagulants From a Basic Science Perspective. Arterioscler Thromb Vasc Biol 2017;37:1812-8.

29. Hart RG, Diener HC, Yang S, Connolly SJ, Wallentin L, Reilly PA, et al. Intracranial hemorrhage in atrial fibrillation patients during anticoagulation with warfarin or dabigatran: the RE-LY trial. Stroke 2012;43:1511-7.

30. Granger CB, Alexander JH, McMurray JJ, Lopes RD, Hylek EM, Hanna M, et al.; ARISTOTLE Committees and Investigators. Apixaban versus warfarin in patients with atrial fibrillation. N Engl J Med 2011;365:981-92.

31. Hankey GJ, Stevens SR, Piccini JP, Lokhnygina Y, Mahaffey KW, Halperin JL, et al.; ROCKET AF Steering Committee and Investigators. Intracranial hemorrhage among patients with atrial fibrillation anticoagulated with warfarin or rivaroxaban: the rivaroxaban once daily, oral, direct factor Xa inhibition compared with vitamin $\mathrm{K}$ antagonism for prevention of stroke and embolism trial in atrial fibrillation. Stroke 2014;45:1304-12.

32. Steinberg BA, Shrader P, Thomas L, Ansell J, Fonarow GC, Gersh BJ, et al.; ORBIT-AF Investigators and Patients. Off-Label Dosing of Non-Vitamin K Antagonist Oral Antico- agulants and Adverse Outcomes: the ORBIT-AF II Registry. J Am Coll Cardiol 2016;68:2597-604.

33. Cho MS, Yun JE, Park JJ, Kim YJ, Lee J, Kim H, et al. Outcomes After Use of Standard- and Low-Dose Non-Vitamin K Oral Anticoagulants in Asian Patients With Atrial Fibrillation. Stroke 2018;A118023093.

34. Wang KL, Giugliano RP, Goto S, Chiu CC, Lin CY, Lai $\mathrm{EY}$, et al. Standard dose versus low dose non-vitamin K antagonist oral anticoagulants in Asian patients with atrial fibrillation: A meta-analysis of contemporary randomized controlled trials. Heart Rhythm 2016;13:2340-7.

35. Smith P, Arnesen H, Holme I. The effect of warfarin on mortality and reinfarction after myocardial infarction. N Engl J Med 1990;323:147-52.

36. Hurlen M, Abdelnoor M, Smith P, Erikssen J, Arnesen H. Warfarin, aspirin, or both after myocardial infarction. N Engl J Med 2002;347:969-74.

37. Lip GY, Lane DA. Does warfarin for stroke thromboprophylaxis protect against MI in atrial fibrillation patients? Am J Med 2010;123:785-9.

38. Cully M. Milestone 13: Putting on the brakes: NOAC antidotes. Nat Rev Cardiol 2017. ]Epub ahead of print]

39. Approves Idarucizumab FD. First NOAC Reversal Agent. MD Magazine; [Internet]. Available from: https://www.mdmag.com/medical-news/fda-approves-idarucizamub-firstnoac-reversal-agent [cited 2019, Jun 30].

40. Reversing NOACs presents challenges - Mayo Clinic; [Internet]. Available from: https://www.mayoclinic.org/medical-professionals/trauma/news/reversing-noacs-presentschallenges/mac-20431007 [cited 2019, Jun 30].

Conflicts of interest.-The authors certify that there is no conflict of interest with any financial organization regarding the material discussed in the manuscript.

Authors' contributions.-Ádám Nagy and Jun H. Kim: literature search, data collection, data analysis, figures, writing; Myeong E. Jeong and Min H. Heo, literature search; Alessandro Putzu and Alessandro Belletti: data interpretation, data analysis; Giuseppe Biondi-Zoccai and Giovanni Landoni: study design, data interpretation, data analysis. The manuscript was drafted by Adám Nagy and Jun Hyun Kim and all authors revised and approved the final version.

Article first published online: October 11, 2019. - Manuscript accepted: October 4, 2019. - Manuscript received: September $27,2019$. For supplementary materials, please see the HTML version of this article at www.minervamedica.it 